\title{
Determine the Association Between Nurses Self-Concept and Clinical Performance Among Nursing Students
}

\section{ABSTRAC}

\author{
Shumaila Ashraf, Muhammad Hussain, Muhammad Afzal, Syed Amir Gilani
}

The University of Lahore

\begin{abstract}
Self-concept in clinical performance had an important role in applying competencies and self-concept in clinical performance influenced to quality care of nursing students. Self-concept is the key point for patient care by the student nurses which is established with continues education, gaining knowledge, learning skills and making attitudes. The purpose of the study is to determine the association between nurses self concept and clinical performance among nursing students. Descriptive cross sectional study was conducted in the school of nursing at Jinnah hospital Lahore. The study data were collected using a questionnaire which consisted of Nursing Self Concept Questionnaire (NSCQ) and Six Dimension Scale of nurse performance 6-(DSNP). Pearson Correlation test was used to explore the relationship of variables. The results of the study show that clinical performance and professional self-concept are related. These findings can be helpful to teachers, authorities at nursing colleges, and nursing managers.
\end{abstract}

Keywords: Professional Self concept; clinical performance; nursing students.

DOI: $10.7176 / \mathrm{JHMN} / 61-09$

Publication date: April $30^{\text {th }} 2019$

\section{Introduction}

Self-concept is a multidimensional ideology consisting physical, emotional, social and spiritual aspect that make up who we are. Self concept reforms and regulate over self as we grow based on the knowledge we gain in over life. Self concept starts developing since childhood. Good environment among the colleagues in the clinical side will promote the self-concept of the nursing students (Gunawan, Aungsuroch, Sukarna, \& Efendi, 2018).

Self-concept in clinical performance had an important role in applying competencies and self-concept in clinical performance influenced to quality care of nursing students. Self-concept is the basic self perception of any individual through which he takes any decision (Albloushi, 2017).

Self-concept is the key point for patient care by the student nurses which is established with continues education, gaining knowledge, learning skills and making attitudes. The expectation can be made for the students to have a high level of confidence (Skoglund, Holmström, Sundler, \& Hammar, 2018).

Before entering in the clinical practices nursing student should be guided by simulation method in medical techniques. Moreover it is found repetitions of these practices improve their capabilities for practical work (Mohamadirizi, Kohan, Shafei, \& Mohamadirizi, 2015).

Nursing students develop self concept regarding this profession in their study tenor. They like it as they join this profession by their own will. With the lapse of time the positive self concept develops in this profession. Moreover, there is a group of students which develop a negative self concept due to their experiences during training regarding staff nurses and comments from the other people regarding this profession. This attitude develops a misconception for the nurses (Parandavar, Rahmanian, \& Jahromi, 2016).

There are different categories in confidence, education, skills and knowledge of Self-concept in nursing students. Most of the nurses think themselves with an excellent confidence for the care of the patients. In the opinion of some nurses the lack of education leads to a low level of self confidence (Gunawan et al., 2018). 
The study was conducted in the department of nursing school. In this study Pearson correlation showed a positive correlation between scores of clinical performance and clinical Self-concept in a way that an increase in score of clinical performance increases score of clinical Self-concept, $\mathrm{P}=0.001$ (Mohamadirizi et al., 2015).

The cross sectional study was conducted in the university. In this study 48 of the participants $(55.8 \%)$ were junior and $38(44.2 \%)$ were senior nursing students. The majority of the students were female $(65.1 \%)$ and single (79.1\%).The results shows that there is a relationship between the students' clinical performance and professional self-concept was slight (Poorgholami, Ramezanli, Jahromi, \& Jahromi, 2016).

A study conducted on 150 of nursing and midwifery students in Isfahan University of Medical Science, selected through two stage sampling. The students who take part in this study complete questionnaire regarding personal/educational attitude about nurse's clinical performance. The findings show $50 \%$ and $37.4 \%$ nurse students have good excellent clinical competence and clinical self performance (Mohamadirizi et al., 2015)

The study was conducted in private nursing school to show the Deeping of communication was permitted as a competence of nurses. This is essential for leadership development (Andrade Vasconcelos et al., 2017).

The study conducted to summarize the means of perceptions in nurses and hinders for communication with families in critical care unit. There is need to enhance the skills and knowledge for a effective communication with a family (Adams et al., 2017).

\section{Significance of the study}

This study will provide information to the nursing school administration to understand the importance of self-concept that effect on the clinical performance of the nursing students. The finding of this study will enable the policy makers and higher authority of the hospital to build self-concept to improve the nurse's clinical performance through seminars, workshops and personal counseling, provide comfortable environment which ultimately enhance the quality care of the organization which will improve the image and repute of the organization.

\section{Theoretical Framework}

Theoretical framework employed in this research work will be shown, according to this model the independent variable is a set of four profile factors (age, sex, marital status and academic year. The dependent variables are self-concept and job performance. Self concept is also effect on job performance. Self-concept is composed of the following six dimensions according to Paso ( $\mathrm{Ng}, 2014)$.

\section{Materials and Methods}

A quantitative cross-sectional research design was used for this study

\section{Independent Variables}

- $\quad$ Self Concept

\section{Dependent Variables}

- Clinical Performance

\section{Sample Size \& Sampling Techniques:}

Data was collected from the participant through questionnaire and the participants were selected through convenient sampling method, the sample size for this study were 200 nurses students which is calculated from the Slovene's formula.

\section{Inclusion Criteria}

$>$ Following students from school of nursing in Jinnah hospital Lahore were included in data collection, those who were present at the time of data collection, and those who were willing to participat Students and who were 16-25 years old 


\section{Exclusion Criteria}

$>$ Following students from school of nursing in Jinnah hospital Lahore will be not included in data collection, those who were not present at the time of data collection and those who were not willing to participate and Students, who were less than 16 year and more than 25 years old

\section{Result and Discussions}

Table1: The mean and standard deviation of the Nurse self concept questionnaire

Statistics

\begin{tabular}{|l|r|r|r|r|r|r|}
\hline & $\begin{array}{c}\text { nursing students } \\
\text { self concept }\end{array}$ & $\begin{array}{c}\text { caring self } \\
\text { concept }\end{array}$ & mean3 & $\begin{array}{l}\text { communicatio } \\
\text { n self concept }\end{array}$ & $\begin{array}{c}\text { knowledge } \\
\text { self concept }\end{array}$ & $\begin{array}{c}\text { leadership } \\
\text { self } \\
\text { concept }\end{array}$ \\
\hline $\mathrm{N} \quad$ Valid & 110 & 110 & 110 & 110 & 110 & 110 \\
Missin & 0 & 0 & 0 & 0 & 0 & 0 \\
Mean & 3.8567 & 4.0773 & 4.1254 & 4.0773 & 4.0684 & 4.1719 \\
Std. Deviation & .76556 & .70265 & .57639 & .65418 & .58469 & .48512 \\
\hline
\end{tabular}

The table shows the mean and std. deviation of the nursing students self concept is $3.8567 \pm .76556$, caring self concept mean and std. deviation is $4.0773 \pm .70265$, staff relation mean and std. deviation is $4.1254 \pm .57639$, communication self concept mean and std. deviation is $4.0773 \pm .65418$, knowledge self concept mean and std. deviation is $4.0684 \pm .58469$ and leadership self concept mean and std. deviation is $4.1719 \pm .48512$.

Table 02:The mean and Std. Deviation of Six Dimensions Scale of Nurse Performance

\section{Statistics}

\begin{tabular}{|l|r|r|r|r|r|r|}
\hline & $\begin{array}{c}\text { teaching and } \\
\text { collaboration }\end{array}$ & $\begin{array}{c}\text { planning and } \\
\text { evaluation }\end{array}$ & $\begin{array}{c}\text { critical } \\
\text { care }\end{array}$ & $\begin{array}{c}\text { interpersonal } \\
\text { relation and } \\
\text { communicatio } \\
\mathrm{n}\end{array}$ & $\begin{array}{c}\text { Leadership } \\
\text { profession } \\
\text { al } \\
\text { developm } \\
\text { ent }\end{array}$ \\
\hline N $\quad$ Valid & 110 & 110 & 110 & 110 & 110 & 110 \\
Missin & 0 & 0 & 0 & 0 & 0 & 0 \\
Mean & 4.0891 & 4.0108 & 4.0837 & 4.0886 & 3.9321 & 3.9694 \\
Std. Deviation & .61353 & .59215 & .57355 & .46976 & .68894 & .54655 \\
\hline
\end{tabular}

The table shows the mean and std. deviation of the teaching and collaboration is 4.0891 \pm .61353 , planning and

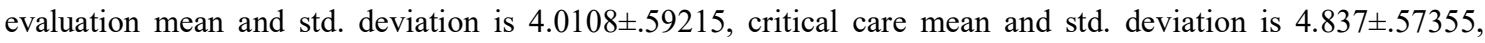
interpersonal relation and communication mean and std. deviation is 4.0886 \pm .46976 . Leadership mean and std. deviation is $3.9321 \pm .68894$ and professional development mean and std. deviation is $3.9694 \pm .54655$

The relationship between the nurse self concept questionnaire scale and six dimensions of students performance

\section{Pearson Correlations}

\begin{tabular}{|ll|r|r|}
\hline & Nurse self concept & $\begin{array}{c}\text { Dimension of students } \\
\text { performance }\end{array}$ \\
\hline \multirow{2}{*}{ nurse self concept } & Pearson Correlation & 1 & $.345^{* *}$ \\
& Sig. (2-tailed) & & .000 \\
& $\mathrm{~N}$ & 110 & 110 \\
dimension of students & Pearson Correlation & $.345^{* *}$ & 1 \\
performance & Sig. (2-tailed) & .000 & 110 \\
\hline
\end{tabular}

**. Correlation is significant at the 0.01 level (2-tailed).

Table 4 shows the Pearson correlation between the nurse self concept and clinical performance was slight but statistically significant $\mathrm{r}=.000$ and $\mathrm{p}=0.01$ 
Conclusion

The results of the study show that clinical performance and professional self-concept are related. Accordingly, attempts should be made to enhance students' professional self-concept during their education that will enhance students' clinical performance. These findings can be helpful to teachers, authorities at nursing colleges, and nursing managers.

\section{References:}

01. Adams, A., Mannix, T., \& Harrington, A. (2017). Nurses' communication with families in the intensive care unit-a literature review. Nursing in critical care, 22(2), 70-80.

02. Al-Makhaita, H. M., Sabra, A. A., \& Hafez, A. S. (2014). Job performance among nurses working in two different health care levels, Eastern Saudi Arabia: a comparative study. International Journal of Medical Science and Public Health, 3(7), 832-838.

03. Albloushi, M. (2017). Saudi Female Nursing Students' Sense of Belonging in Clinical Settings: A MixedMethods Study.

04. Andrade Vasconcelos, R. M., Caldana, G., Cantarella Lima, E., da Silva, M., Duarte, L., Bernardes, A., \& Silvia Gabriel, C. (2017). COMMUNICATION IN THE RELATIONSHIP BETWEEN LEADERS AND LEAD IN THE CONTEXT OF NURSING. Journal of Nursing UFPE/Revista De Enfermagem UFPE, 11 .

05. Ayman, M., Ahmad, E., Imad, N., Wisam, M., Saleh, N., \& Muna, A. (2014). Patients' satisfaction about nurses’ competency in practicing communication skills. Life Science Journal, 11(3), 339-334.

06. Badiyepeymaiejahromi, Z., Kargar Jahromi, M., \& Ramezanli, S. (2016). Nursing students’ professional self-concept and clinical performance. Bangladesh Journal of Medical Science, 15(1).

07. Dondorf, K., Fabus, R., \& Ghassemi, A. E. (2016). The interprofessional collaboration between nurses and speech-language pathologists working with patients diagnosed with dysphagia in skilled nursing facilities. Journal of Nursing Education and Practice, 6(4), 17-20.

08. Gunawan, J., Aungsuroch, Y., Sukarna, A., \& Efendi, F. (2018). The image of nursing as perceived by nurses: A phenomenological study. Nursing and Midwifery Studies, 7(4), 180-185.

09. Lapeña-Moñux, Y. R., Cibanal-Juan, L., Pedraz-Marcos, A., \& Macía-Soler, M. (2014). Interpersonal relationships among hospital nurses and the use of communication skills. Texto \& Contexto-Enfermagem, 23(3), 555-562.

10. Leddy, R., \& Wilkinson, J. M. (2015). Endotracheal suctioning practices of nurses and respiratory therapists: how well do they align with clinical practice guidelines? Canadian journal of respiratory therapy: $C J R T=$ Revue canadienne de la therapie respiratoire: $R C T R, 51(3), 60$.

11. Mohamadirizi, S., Kohan, S., Shafei, F., \& Mohamadirizi, S. (2015). The relationship between clinical competence and clinical self-efficacy among nursing and Midwifery students. International Journal of Pediatrics, 3(6.2), 1117-1123. 
12. Ng, J. A. I. (2014). Human Resource Management in the Context of Self-Concept and Its Impact on the Job Performance of College Full-Time Faculty Members of De La Salle Lipa. AXIS: Journal of Lasallian Higher Education, 5(3).

13. Parandavar, N., Rahmanian, A., \& Jahromi, Z. B. (2016). A study of the relationship between nurses' professional self-concept and professional ethics in hospitals affiliated to Jahrom University of Medical Sciences, Iran. Global journal of health science, 8(4), 82.

14. Park, M. S., Jeoung, Y., Lee, H. K., \& Sok, S. R. (2015). Relationships among communication competence, self-efficacy, and job satisfaction in Korean nurses working in the emergency medical center setting. Journal of Nursing Research, 23(2), 101-108.

15. Parveen, R., Hussain, M., Majeed, I., Afzal, M., \& Gilani, S. A. (2018). Influence of Poverty on Moral Development in Rural Community Lahore. International Journal of Social Sciences and Management, 5(3), 113-124.

16. Poorgholami, F., Ramezanli, S., Jahromi, M. K., \& Jahromi, Z. B. (2016). Nursing students' clinical performance and professional self-concept. Bangladesh Journal of Medical Science, 15(1), 57-61.

17. Schwirian, P. M. (1978). Six dimension scale of nursing performance. Columbus: Ohio University College of Nursing.

18. Skoglund, K., Holmström, I. K., Sundler, A. J., \& Hammar, L. M. (2018). Previous work experience and age do not affect final semester nursing student self-efficacy in communication skills. Nurse education today, 68, 182-187.

19. Soroush, F., Zargham-Boroujeni, A., \& Namnabati, M. (2016). The relationship between nurses' clinical competence and burnout in neonatal intensive care units. Iranian journal of nursing and midwifery research, 21(4), 424.

20. Yadav, R. L., Piryani, R. M., Deo, G. P., Shah, D. K., Yadav, L. K., \& Islam, M. N. (2018). Attitude and perception of undergraduate medical students toward the problem-based learning in Chitwan Medical College, Nepal. Advances in medical education and practice, 9, 317. 